\title{
Connectedness With Nearby Nature and Well-Being
}

\author{
Elizabeth K. Nisbet*, Daniel W. Shaw and Danielle G. Lachance \\ Department of Psychology, Trent University, Peterborough, ON, Canada
}

Trees are an integral and salient feature of the natural environment with multiple benefits for environmental and human health. Little is understood, however, about how connectedness with trees or other features of nature (e.g., wildlife) are associated with human health perceptions and well-being. Similarly, research on links between neighborhood trees and nature connectedness is lacking. Community participants ( $n=102$ older adults, $M_{\text {age }}=61.56, S D=9.71$ ) in Peterborough, Canada completed questionnaires related to general health (perceived), subjective well-being, interconnectedness with nature, and other demographics. A subsample of participants $(n=36)$ provided postal codes that allowed for the tree canopy sampling of four neighborhoods. People living near trees reported better mental health perceptions (GHQ-12) and a greater sense of connectedness to the natural world around them.

OPEN ACCESS

Edited by:

Elise Louise Amel, University of St. Thomas,

United States

Reviewed by: Cynthia McPherson Frantz, Oberlin College, United States

Paula Maria Bögel, Karlsruhe Institute of Technology (KIT), Germany

*Correspondence:

Elizabeth K. Nisbet

elizabethnisbet@trentu.ca

Specialty section:

This article was submitted to Urban Resource Management, a section of the journal

Frontiers in Sustainable Cities

Received: 01 January 2020 Accepted: 21 April 2020

Published: 27 May 2020

Citation:

Nisbet EK, Shaw DW and Lachance DG (2020) Connectedness With Nearby Nature and Well-Being.

Front. Sustain. Cities 2:18. doi: 10.3389/frsc.2020.00018 Connectedness with trees, wildlife, and nature was associated with better psychological well-being and less mental distress. This sense of connection was still related to better mental health-more positive moods and feelings of vitality - when controlling for age, income, and neighborhood connectedness. Trees are an integral part of communities and are a cost-effective way of enhancing health as well as mitigating the effects of climate change. Cultivating connectedness with specific elements of the natural environment may help to promote greater environmental concern and behavior, while providing a positively-framed motivation for such action.

Keywords: nature connectedness, trees, well-being, health perception, emotion, natural environment

\section{CONNECTEDNESS WITH NEARBY NATURE AND WELL-BEING}

Many elements of the natural environment (nature ${ }^{1}$ ) have direct and indirect benefits for humans (Kuo, 2015). Trees, for example, are often a dominant feature of urban areas and contribute to wellbeing at the community or neighborhood level (Berman et al., 2008; Escobedo and Nowak, 2009; Park et al., 2010; Stagoll et al., 2012; Klemm et al., 2015). Both the United Nations Environment Programme (UNEP) and the Intergovernmental Panel on Climate Change (IPCC) suggest planting more trees is a simple way to mitigate the effects of, and adapt to, a changing climate (IPCC, 2014; UNEP, 2015). However, forests continue to diminish, particularly in urban areas (Tominaga et al., 2008). The risks of climate change may seem uncertain, intangible, and a distal threat (Gifford, 2008). Particularly in regions such as Southern Ontario, where average temperatures have not increased significantly, deforestation may seem less worrying than other risks, such as the spread

${ }^{1}$ For this study, nature is defined as natural or non-built elements of the physical environment, such as trees and other plants, wildlife, bodies of water (oceans, lakes, rivers, streams), and landscapes. 
of blacklegged ticks (Ixodes scapularis). It may be necessary to focus on the many human health and well-being benefits of trees (and other elements of nature) in order to emphasize their importance and motivate climate change action.

Despite evidence of nature's benefits, people are spending less time interacting with the natural environment than they have in previous generations (Pergams and Zaradic, 2008). On average, those living in Western, industrialized countries spend over $90 \%$ of their time indoors (Matz et al., 2014). A growing decline in human-nature interactions may pose substantial threats to human and environmental health (Soga and Gaston, 2016). One explanation for the increasing human-nature disconnect is the global rise in urbanization (Turner et al., 2004), which can lead to environmental degradation and reduced access to natural outdoor spaces. To date, $55 \%$ of the world's population lives in cities, a number projected to increase to $68 \%$ by 2050 (United Nations, 2018). Therefore, developing a better understanding of how people connect with and benefit from urban nature may be crucial in improving the health of cities and societies worldwide. This is particularly important given that urban residents will need to develop coping skills and resiliency in the face of environmental change.

\section{TREES AND NEIGHBORHOOD WELL-BEING}

Trees benefit neighborhood environments from a human wellbeing perspective in a number of ways. Trees, and other vegetation, contribute to neighborhood well-being by improving control of snow and rainwater flow, air quality, temperature in summer-time heat, and biodiversity (Escobedo and Nowak, 2009; Stagoll et al., 2012; Klemm et al., 2015). In Santiago, Chile, high, medium, and low economic sub regions had their tree cover measured and compared to data from local environmental monitoring stations (Escobedo and Nowak, 2009). Hundreds of metric tons of toxic compounds $\left(\mathrm{PM}_{10}, \mathrm{O}_{3}, \mathrm{CO}, \mathrm{NO}_{2}, \mathrm{SO}_{2}\right)$ were removed from the air by trees and vegetation; in fact, more air pollution was removed by trees in the low socioeconomic region than in the high socioeconomic region, with only half the number of trees as in the more affluent region. Furthermore, by following emission paths, street-lined trees appear to buffer against air pollution through a funneling effect, particularly for non-carbon emissions such as fine particulate matter and nitrogen-oxygen compounds (Vos et al., 2013).

In addition to improving air quality, trees also help regulate temperature-even within urban neighborhoods. In the fourth largest city in the Netherlands, differences between tree density and canopy cover were analyzed with temperature data from July and August while controlling for cloud cover, humidity, and wind velocity (Klemm et al., 2015). Nine streets with similar built features (row housing) were grouped into high, medium, and low densities based on tree canopy cover and ground vegetation. Mean radiant temperature was significantly lower in areas with high density tree canopy cover, with a $10 \%$ increase related to a $1^{\circ} \mathrm{C}$ drop in temperature (Klemm et al., 2015). Shade from trees has been associated with a reduction in the heat island effect in urban areas, whereby built elements, such as concrete and asphalt surfaces, absorb heat from the sun and increase local ambient temperature (Akbari et al., 2001). Trees and vegetation, on the other hand, reflect sunlight back into the atmosphere while respiring and releasing water in response to the sunlight they do absorb, which leads to reductions in energy costs associated with air-conditioned cooling. In major Canadian cities, lower income residents are disproportionately exposed to poorer air quality and higher temperatures than higher income residents; however, greater rates of trees and vegetation moderate the relationship between income, air quality, and the urban heat island effect (CIHI, 2011). Thus, the combination of shade and respiration provided by trees and vegetation contribute to a summer cooling effect, something intuitive for anyone who has taken refuge under a grand tree with large leaves in the summer.

Someone who has spent some time under a tree has probably noticed a bird or two. An indication of neighborhood wellbeing is the amount of biodiversity it supports. Neighborhood parks in residential areas were studied in Australia where 109 separate parks were assessed for tree density per hectare, percentage of grass cover, presences of shrubs, and leaf litter. These dimensions were compared along with observations made during two 10-min wildlife sampling periods at each park (Stagoll et al., 2012). Large, mature trees were found to house more wildlife than other features of the environment, and as tree size increased, so did bird and woodland species richness (Stagoll et al., 2012). Interestingly enough, semi-structured interviews with adults in Southern England revealed bird songs and calls as the most identified auditory feature of the natural environment for reducing stress and restoring attention (Ratcliffe et al., 2013). Increasingly, research suggests that greater biodiversity provides human physical and psychological health benefits (Fuller et al., 2007; Luck et al., 2011). Trees improve the air quality of their surroundings, provide thermal regulation in the summer, and increase neighborhood biodiversity, all of which can be seen as improvements to neighborhood well-being with direct and indirect implications for human well-being.

\section{TREES AND HUMAN PHYSICAL AND PSYCHOLOGICAL WELL-BEING}

Sedentary lifestyles, stroke, heart disease, attentional deficits, and depression are all challenges to human well-being, among other pathologies (Forouzanfar et al., 2015). It is important to note that well-being is not simply the absence of disease, injury, or other illness, but well-being also includes other physical, mental, and social dimensions, such as a sense of vitality and happiness (Shields, 2008). Because human well-being is abstract, one measure seldom encompasses the full spectrum of positive functioning. Perceived physiological well-being can be assessed with self-reported health questionnaires (e.g., Pennebaker, 1982; Goldberg et al., 1997), while psychological well-being is often conceptualized and operationalized into hedonic and eudaimonic classifications. Hedonic refers to how often pleasant and unpleasant emotions are experienced (e.g., Watson et al., 1988). Eudaimonic dimensions are characteristics of high-quality 
living and more discretely related to pleasure; though not always perceived as pleasurable, for example, purpose in life and vitality can be considered indications of positive functioning (Ryan and Frederick, 1997).

Exposure to forested areas can improve physiological markers of well-being, including blood pressure, cortisol, and heart rate variability (Park et al., 2010). Walks in an arboretum (a garden devoted to trees) can enhance attention and memory (Berman et al., 2008, 2012). Furthermore, people feel better emotionally, more alive, and more cooperative under the influence of nature (Berman et al., 2008; Nisbet et al., 2011; Zelenski et al., 2015). Perhaps the most notable research evidence for the physiological enhancements associated with trees and forested areas comes from Japan. Shinrin-Yoku, or forest bathing, is the act of immersing oneself in the forest and experiencing it through all the senses-taking in the air as well as visual and other sensory stimuli (Park et al., 2010). Across 24 separate studies, close to 500 participants had their stress, immune system, blood pressure, heart rate, and nervous system activity measured before and after exposure to forested and urban settings (Park et al., 2010). The forest experiences improved participants' stress response: lower cortisol levels (the stress hormone), pulse rates, diastolic and systolic blood pressure, as well as increased parasympathetic nervous system activity (related to digestion) and decreased sympathetic nervous system activity (related to the fight or flight response). Based on these findings, it appears trees, being a salient element of the forest, contribute to a positive influence on human health and well-being. Though less research on these effects has been conducted in North American environments, other studies have focused on the cognitive and emotional benefits of nature.

Nature promotes recovery from stress but can also improve functioning. Attention Restoration Theory (Kaplan, 1995) implies natural features of the environment rest attentional parts of the brain and in turn have restorative benefits. Kaplan and colleagues have demonstrated that walking in treed environments significantly improves mood and working memory (Berman et al., 2008). Walks in treed areas also led to a significant reduction of repeated negative thoughts (rumination) in depressed individuals (Berman et al., 2012). Furthermore, exposure to nature enhances learning (Kuo et al., 2018), selfcontrol (Kaplan, 2001; Faber Taylor et al., 2002) and can reduce ADHD symptoms in children (Faber Taylor et al., 2001; Kuo and Faber Taylor, 2004; Faber Taylor and Kuo, 2009).

In addition to the physical health benefits, there seem to be mental health benefits from exposure to actual nature (vs. still or video images, cf. Jiang et al., 2016) such as psychological well-being and subjective connectedness. Connecting with the natural environment is important for mitigating the stress that is often part of urban living, but also for fostering resilience and flourishing (Capaldi et al., 2015).

\section{TREES, CONNECTEDNESS, AND ENVIRONMENTAL CONCERN}

Increased deforestation and urbanization contribute to a disconnection of people from the natural landscape. Pyle (1993) refers to this as "extinction of experience." When disconnected from nature, people may avoid it and miss opportunities for improving their physical and mental health. As a consequence, unfamiliarity with the natural world may lead people to devalue and degrade it (Soga and Gaston, 2016). Conversely, people with a greater connection to nature not only care for and protect it, they also spend more time in it (Nisbet et al., 2009; Tam, 2013; Lin et al., 2014; Colléony et al., 2017; Whitburn et al., 2018). People with a strong sense of connection to nature report being happier and feeling more alive and energetic (Mayer and Frantz, 2004; Nisbet et al., 2009, 2011; Zelenski and Nisbet, 2014). Even a brief exposure to nature-a walk through local, urban area-improves mood and increases (state) nature connectedness (Nisbet and Zelenski, 2011; Nisbet et al., 2019).

Nature connectedness is associated with more frequent use of backyards and increased visits to local green spaces (Lin et al., 2014, 2017; Flowers et al., 2016). Nature-related people are also more likely to travel farther distances to visit remote parks (with more remnant vegetation) than people who are less connected (Lin et al., 2014; Shanahan et al., 2015). Contact with the natural environment may be essential in fostering nature connectedness, but a connection with nature may also help people maintain regular nature contact, promoting better human and environmental health.

Trees and other natural elements have observable benefits when people are immersed in, exposed to, or view environments that feature those elements. The amount of time people spend in nature is associated with how much they relate to and are concerned for the natural world (Schultz, 2001). How these ideas transfer to community settings where elements like trees and vegetation influence well-being is not yet well-understood. In Toronto, Canada the relationship between neighborhood trees and perceived health was assessed using comprehensive street tree data, satellite information, and results from a province-wide survey, with over 30,000 responses from the Ontario Health Study (Kardan et al., 2015). Controlling for a host of demographic factors, street tree canopy cover from over 3,000 Canadian Census Dissemination Areas had a strong, positive relationship with people's general health perceptions, with less reported mental illnesses, and less cardio-metabolic conditions. In fact, having 10 more trees per neighborhood block was associated with better (perceived) general health equivalent to increasing the neighborhood median income and individual income by $\$ 10,000$ each and being 7 years younger. Adding one more tree to that scenario doubled the dollar value and reduced age by another year (Kardan et al., 2015).

Kuo (2015) has identified 21 possible links between nature and the promotion of human health and well-being. The immune system is posited as the health dimension influenced most by nature. Vegetation and trees on neighborhood streets, in gardens, in parks, in forested areas, and in agricultural areas all relate to a number of well-being indicators. Positive benefits are associated with reductions in depression and anxiety symptoms, ADHD, recovery from surgery, diabetes, cancer, and infectious diseases, when controlling for confounding variables like socioeconomic status. This also hints at the important relationship between nature and longevity (Kuo, 2015). Indeed, 
when the U.S. Forestry Service looked at all-cause mortality rates before and after the Emerald Ash Borer (Agrilus planipennis) decimated tree populations in northern states bordering Canada, human mortality rates, particularly related to cardiovascular and respiratory complications, dramatically increased in areas with tremendous tree loss (Donovan et al., 2013). Similar tree loss was related to increased rates of poor birth outcomes (Donovan et al., 2011). Though age was controlled for in some large-scale studies, how trees and nature influence individual differences in the well-being of older adults is not as well-understood. As the climate warms, it is predicted that we will lose a tremendous number of trees that have adapted to a small temperature range, particularly coniferous trees (Wang et al., 2014). Much of the wildlife supported by trees is already at risk (e.g., birds; Rosenberg et al., 2019). Thus, work is needed to understand how our relationship with trees is linked with health, and what to expect with a changing environment.

\section{TREES AND OLDER ADULTS}

Natural features of the environment, particularly trees and vegetation, play a crucial role in neighborhood and human physiological and psychological well-being. Some researchers have even argued that nature is a source of preventative medicine (Park et al., 2010; Tsunetsugu et al., 2010). For older adults, some natural elements of the neighborhood (trees, vegetation, gardens) are more aesthetically pleasing than others, which results in preferred walking route selection, and residential satisfaction (Borst et al., 2008). Adults over 65 rate photos with more vegetation as being more inviting for walking (Van Cauwenberg et al., 2014). Survey research with homeowners in Ohio assessed the presence of trees, vegetation rates, and building density within a walking buffer area around their residences (Hur et al., 2010). Tree density and vegetation rate significantly predicted satisfaction and perceived naturalness, and, not surprisingly, the more buildings there were, the less vegetation there was. Thus, if older adults prefer walking along routes with more trees and vegetation, then people living in close proximity to these features may spend more time in contact with nature, fostering stronger connections and reaping the health benefits of doing so.

Living around greenspace has health benefits (Mitchell and Popham, 2008) but measures of greenspace often include grass, gardens, and other open areas, not necessarily trees specifically. In Toronto, however, street tree canopy predicted better mental health perceptions (Kardan et al., 2015). Increases in street tree density has also been associated with fewer anti-depressant prescriptions in London, UK, another large metropolitan area (Taylor et al., 2015). In large cities like London and Toronto, trees may be more aesthetically appealing as they stand out against a metropolitan backdrop. Thus, it is valuable to assess whether a beneficial relationship between trees and mental health exists in a smaller urban area.

Trees are clearly an integral feature of the environment, supporting the health and well-being of neighborhoods, humans, and the planet. Trees also contribute to the aesthetic appeal of neighborhoods. People report less stress, a greater ability to focus, and feeling more alive after exposure to nature, and those with a stronger connection to the natural environment tend to have more positive functioning (Capaldi et al., 2015). Although there is a substantial amount of research on the importance of neighborhood greenspaces, little is known about the specific natural features that may contribute to well-being, and the individual differences older adults may have in their connection with trees, wildlife, and nature in general.

\section{THE PRESENT STUDY}

Our goal was to examine how benefits associated with the natural environment manifest in residents of Peterborough, Ontario. Peterborough is a small urban setting in central Ontario (Figure 1; population 81,032; Statistics Canada, 2017), with surrounding suburbs and rural areas. In the Peterborough area, where climate change may not yet be salient in the immediate physical environment, trees and vegetation may be less novel than in a metropolitan area like Toronto. We sought to explore potential positive relationships between neighborhood trees (particularly tree canopy density), health perceptions, and wellbeing in an understudied older adult population, along with potential links between individual differences in connectedness to various aspects of the natural environment. Based on previous research, we aimed to answer several research questions: (1) Are there individual differences in connectedness to specific features in nature (trees, wildlife) that are associated with health and wellbeing? (2) If connectedness with nature contributes to well-being, is this independent of connections with the local surroundings (i.e., to the neighborhood and one's neighbors)? (3) Is tree canopy cover rate associated with health perceptions and psychological well-being in older adults? and (4) Is the presence of greater tree canopy coverage associated with individual differences in subjective connectedness to features of the environment (trees, wildlife, nature in general)?

\section{METHOD}

\section{Participants}

Participants were recruited from the Peterborough, Ontario community for a study on older adults and the well-being features of neighborhood environments. Advertisements were posted in area grocery stores, coffee shops, community centers, a bingo hall, and online using social media (the majority of respondents indicated they heard about the study on Facebook;

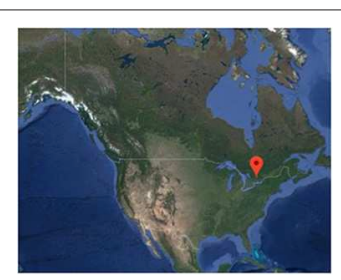

FIGURE 1 | Location of Peterborough, Canada (44.30012 ${ }^{\circ} \mathrm{N},-78.31623^{\circ} \mathrm{W}$ ) Image source: Google Maps ๑ (2019). 
$n=68 ; 66.7 \%)$. Participants were entered in a draw for a $\$ 100$ cash prize as incentive for completing the study; the winner was awarded their prize after the study was completed. Data collection took place during the late fall and early winter (December and January).

This study was carried out in accordance with the recommendations of the Trent University Research Ethics Board. The protocol was approved by the Trent University Research Ethics Committee. All subjects gave written informed consent in accordance with the Declaration of Helsinki.

Cases were excluded ( $n=19$ ) for excessive missing data, or if respondents did not meet the advertised age criteria "older adults" (we retained data from those who were at least in middle-adulthood, 40 years of age and older), resulting in a sample of 102 (see Tables 1, 2 for descriptive statistics of the study variables). Almost two thirds of participants had more than high-school education. Most were living in a single-unit home and approximately half were retired. The majority of respondents $(68.6 \%)$ had lived in their current residence for more than 5 years.

\section{Materials \\ Health Perceptions}

The Pennebaker Inventory of Limbic Languidness (PILL; Pennebaker, 1982; Pennebaker and Epstein, 1983) assesses subjective physiological well-being and correlates with more visits to health clinics and sick days away from work (Pennebaker, 1982; Pennebaker and Epstein, 1983). Respondents rated the frequency of 54 common health complaints, such as "eyes water," "runny nose," and "dizziness" on a 5-point Likert scale from 0 (never or almost never experienced) to 4 (more than once every week). Higher scores (a sum of all items) on the PILL indicate greater physical distress $(\alpha=0.91)$.

TABLE 1 | Descriptive statistics for continuous study variables.

\begin{tabular}{lccc}
\hline (N = 102) & M & SD & Range \\
\hline Age & 61.56 & 9.71 & $40-91$ \\
Income (annual household \$) & $59,299.00$ & $39,593.00$ & $8,000-200,000$ \\
Tree Canopy (\% cover) & 22.75 & 9.83 & $1.00-43.70$ \\
Psychological Distress (GHQ; scale & 23.08 & 5.47 & $13.00-43.00$ \\
1-48) & & & \\
Physical Distress (PILL; scale 0-216) & 59.87 & 27.57 & $7.00-156.00$ \\
Positive Affect (scale 1-5) & 3.31 & 0.61 & $1.13-4.38$ \\
Negative Affect (scale 1-5) & 1.89 & 0.71 & $1.00-3.88$ \\
Nature Positive Affect (scale 1-5) & 2.84 & 0.86 & $1.00-4.67$ \\
Vitality (scale 1-57 & 4.32 & 1.27 & $1.00-7.00$ \\
Connectedness-Trees (scale 1-7) & 4.29 & 1.77 & $1.00-7.00$ \\
Connectedness-Wildlife (scale 1-7) & 4.03 & 1.85 & $1.00-7.00$ \\
Connectedness-Nature (scale 1-7) & 4.28 & 1.80 & $1.00-7.00$ \\
Connectedness-Neighborhood and & 3.51 & 1.41 & $1.00-7.00$ \\
Neighbors; scale 1-7) & & & \\
Active time in nature & 4.71 & 7.60 & $0-40.00$ \\
Time in garden or yard & 1.03 & 2.24 & $0-12.00$ \\
Time visiting a park & 0.22 & 0.84 & $0-7.00$ \\
& & &
\end{tabular}

The General Health Questionnaire (GHQ-12; Goldberg et al., 1997) measures primarily depressive symptoms using 12 items such as "have you been able to enjoy your normal day-to-day activities" and "have you been feeling unhappy or depressed." Participants indicated their experiences over the previous 2 weeks using a 4-point Likert response scale with higher scores indicating more psychological distress $(\alpha=0.90)$. Both the PILL and GHQ are measures of distress, or the presence of illness, and are valid with samples of varying age, gender, and education (Pennebaker, 1982; Goldberg et al., 1997).

\section{Well-Being}

A modified version of the PANAS (Watson et al., 1988) assessed positive and negative affect. Participants rated how much they felt 16 positive and negative emotions (e.g., joy, contentment, sadness, hostility) over the prior 2 weeks on a Likert continuum.

TABLE 2 | Descriptive statistics for categorical study variables.

\begin{tabular}{|c|c|c|}
\hline & $n$ & $\%$ \\
\hline \multicolumn{3}{|l|}{ Gender } \\
\hline Female & 79 & 77.5 \\
\hline Male & 22 & 21.6 \\
\hline \multicolumn{3}{|l|}{ Education } \\
\hline Some/graduated high school & 30 & 29.4 \\
\hline Some/graduated college & 33 & 32.4 \\
\hline Some/graduated university & 28 & 27.5 \\
\hline Post-graduate (master's) degree & 10 & 9.8 \\
\hline Ph.D. & 1 & 1.0 \\
\hline \multicolumn{3}{|l|}{ Employment status } \\
\hline Full-time & 33 & 32.4 \\
\hline Part-time & 5 & 4.9 \\
\hline Unemployed & 6 & 5.9 \\
\hline Retired & 53 & 52.0 \\
\hline Other & 5 & 4.9 \\
\hline \multicolumn{3}{|l|}{ Household composition } \\
\hline Live alone & 14 & 13.7 \\
\hline Live with partner without children & 57 & 55.9 \\
\hline Live with partner with children & 17 & 16.7 \\
\hline Live with roommate(s) & 3 & 2.9 \\
\hline Live with family (parents, siblings) & 4 & 3.9 \\
\hline Live alone with children & 5 & 4.9 \\
\hline Other & 2 & 2.0 \\
\hline \multicolumn{3}{|l|}{ Type of residence } \\
\hline Single-unit home & 87 & 85.3 \\
\hline Multi-unit home & 4 & 3.9 \\
\hline Low-rise apartment & 7 & 6.9 \\
\hline High-rise apartment & 2 & 2.0 \\
\hline Other & 2 & 2.0 \\
\hline \multicolumn{3}{|l|}{ Length at current residence } \\
\hline Less than 1 year & 9 & 8.8 \\
\hline $1-5$ years & 23 & 22.5 \\
\hline $5-10$ years & 29 & 28.4 \\
\hline Over 10 years & 41 & 40.2 \\
\hline
\end{tabular}


Scores from the eight positive $(\alpha=0.83)$ and eight negative ( $\alpha=0.89$ ) emotion words were averaged separately. Three additional words captured emotions suggested as relevant to nature's restorative benefits (Kaplan, 1995): awe, fascinated, and curious (nature positive affect: $\alpha=0.78$ ).

The Vitality Scale (Ryan and Frederick, 1997; 6 items) measures how alive and energetic one subjectively feels (e.g., "I look forward to each new day" and "I nearly always feel alert and awake"). Higher scores are indicative of feeling energetic in daily life $(\alpha=0.91)$.

\section{Nature Connectedness}

A modified version of Schultz's (2002) Inclusion of Nature in Self (INS) scale assessed connectedness with "nature," but also specific aspects of the natural environment: "trees," "wildlife," "neighbors," and "neighborhood" (cf. Leary et al., 2008). Participants selected from a series of seven Venn diagrams (pairs of circles with varying degrees of overlap; each circle pair contained the words "me" or "nature"). Circles with no overlap indicate less interconnectedness whereas complete overlap represents a closer relationship between the self and the target other (nature, trees, etc.). A composite "neighborhood connectedness" variable was computed by averaging the two INS measures of subjective connection to the local surroundings (neighborhood and neighbors; $\alpha=0.78$ ). Participants also reported on the number of hours spent, during the prior week, "on a walk, hike, or activity in nature," "in the garden or yard," and "visiting a park." To reduce demand characteristics, these items were embedded amongst other distractor activities: e.g., time at the gym, with friends, in a car.

\section{Neighborhood Tree Canopy}

An open source tool for evaluating urban forests, i-Tree Canopy (2006; from itreetools.org/canopy ${ }^{2}$ ) was used to assess the rate of canopy cover for each participant who provided a postal code. $i$-Tree Canopy is a peer reviewed photointerpretation tool that utilizes satellite imagery from Google Earth. Investigating tree cover change in 20 U.S. cities, Nowak and Greenfield (2012), Nowak et al. (2014) demonstrated that i-Tree Canopy was a valid and reliable measure of canopy cover compared to other geographical information system (GIS) applications. Additionally, Nowak and Greenfield (2010) compared i-Tree Canopy measures against the National Land Cover Database (NLCD) and found $i$-Tree provided similar estimates of canopy cover. The tool allows the user to define an area of interest by drawing directly on a map or uploading Environmental Systems Research Institute (ESRI) shapefile coordinates. Once a geographical area is defined it is randomly sampled to assess the rate of canopy cover; between 500 and 1,000 samples per defined area is recommended in order to reduce standard error and improve validity. Each sampling point is identified by the user as being part of a tree canopy or not, then the number of tree canopy identified points is compared to all points sampled to provide a ratio estimate tree canopy cover in the defined area

${ }^{2}$ Developed by Nowak, Walton, and Greenfield at the USDA Forest Service and by Ellingsworth, Binkley, and Maco at the Davey Tree Expert Company
(Figure 2 illustrates a neighborhood being sampled using the i-Tree Canopy tool).

\section{Procedure}

Participants completed all measures online (recruitment ads contained a link to the survey, hosted on the university's Qualtrics platform). After providing informed consent, respondents reported on background (demographic) characteristics and were asked to indicate their six-digit residential postal code. Postal codes for participants within the City of Peterborough $(n=36)$ were matched to a Local Delivery Unit (LDU) for tree canopy mapping. The boundary shapefiles from ESRI Canada were extracted with ArcGIS by an associate at Trent University's Maps, Data, and Government Information Centre. Boundaries were then uploaded to $i$-Tree in order to define the neighborhood area tree canopy cover estimation. The local delivery unit boundary was referred to as the participant's neighborhood. Each neighborhood was sampled at least 500 times in order to achieve a reliable estimate of canopy cover (as recommended by the i-Tree Canopy manual, 2006). The i-Tree mapping process was not undertaken for participants with postal codes outside Peterborough as these codes covered areas too large to provide a reliable neighborhood measure of tree canopy. The 36 participants with measured neighborhood tree canopy rates came mainly from the K9H $(n=14)$ and K9J $(n=19)$ postal areas, which represents north and south parts of Peterborough, respectively, and can be seen in Figures 3, 4. Six participants were from adjacent areas $\mathrm{K} 9 \mathrm{~K}(n=3)$ and $\mathrm{K} 9 \mathrm{~L}(n=3)$. There was no difference in overall neighborhood tree canopy for Peterborough's north end $(\mathrm{K} 9 \mathrm{H} ; M=20.67, S D=9.55)$ and south end residents (K9J; $M=24.56, S D=10.02$ ), or the K9K $(M=23.30, S D=15.66)$ or K9L residents $(M=27.60$, $S D=15.94), F_{(3,32)}=0.51, p>0.10$ (all post-hoc comparisons were non-significant). The rate of canopy cover was matched to the corresponding participants.

\section{RESULTS}

The purpose of the study was to investigate potential health and well-being benefits of particular aspects of nature (e.g., trees)

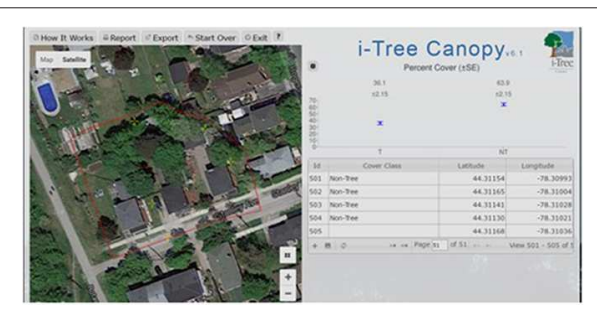

FIGURE 2 | Screenshot of i-Tree Canopy sampling process. This image is zoomed out to show the whole sampling area. When sampling, the image is zoomed closer. Yellow crosshairs indicate the point of latitude and longitude to be sampled and the red border represents the neighborhood boundary. Local delivery boundaries appeared to be of finer scale than Canadian Census Tracts. 


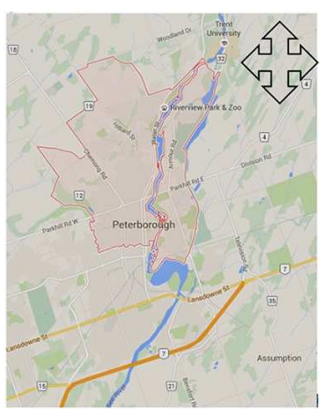

FIGURE 3 | Highlighted boundary representing $\mathrm{K9H}$ postal area in north end of Peterborough. Image courtesy of Google Maps @ (2016).

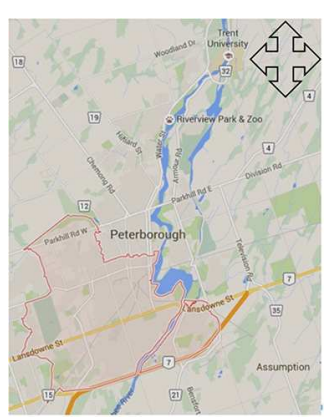

FIGURE 4 | Highlighted boundary representing K9J postal area in south end of Peterborough. Image courtesy of Google Maps @ (2016).

along with individual differences in subjective connectedness with nature. These relationships were investigated with survey methods and linked to objective tree canopy density data from photointerpretation software (i-Tree Canopy) in Peterborough, Ontario.

Descriptive statistics for the study variables are presented in Tables 1, 2. Prior to conducting the main analyses, we tested whether any of the outcome variables differed according to age or gender. Gender was unrelated to any of the wellbeing or connectedness variables. Age was positively related to connectedness with the neighborhood $(r=0.36, p<0.01)$ and neighbors $(r=0.24, p<0.05)$, and negatively correlated with mental health perceptions (GHQ, $r=-0.21, p<0.05$ ) and negative affect $(r=-0.22, p<0.05)$. In subsequent analyses for connectedness and well-being, we controlled for gender, income, age, and neighborhood connectedness (described in more detail, in the relevant section below).

\section{Connectedness With Nature, Health Perceptions, and Well-Being}

To explore whether differences in connectedness were associated with health and well-being, we analyzed correlations between the three types of nature connectedness, neighborhood connectedness, and the various indicators of physical and mental health (Table 3). Connectedness with trees correlated with positive well-being indicators and was generally unrelated to negative physical and mental health perceptions, or negative mood. A similar pattern of correlations emerged for connectedness with wildlife, and nature in general, but these aspects of connection were also negatively related to both measures of ill-being. Connection with wildlife was not as strongly correlated with well-being (smaller magnitude); connectedness with trees and with nature had stronger associations with positive mental health. People with a stronger connection to trees and nature also reported spending more time visiting parks. Those who felt connected with wildlife were somewhat more likely to report being active, on a hike or other activity in nature. Gardening was only marginally associated with connection to wildlife.

Neighborhood connectedness was associated with all health and well-being indicators, with the exception of physical distress. In other words, similar to the nature connectedness results, respondents who are more connected to their neighborhood and neighbors have less psychological distress, more positive and fewer negative emotions, are more fascinated, and feel vital and alive.

We also examined the relationship between age and gender with the outcome variables. Gender was unrelated to any of the well-being or connectedness variables. Age was positively related to neighborhood connectedness $(r=0.32, p<0.01)$ and negatively correlated with mental health perceptions (GHQ, $r=$ $-0.21, p<0.05)$ and negative affect $(r=-0.22, p<0.05)$.

To test whether connection with trees and other aspects of nature have well-being benefits independent of connections with neighbors and the general neighborhood we computed partial correlations controlling for the composite neighborhood connectedness measure as well as gender, income, and age. The zero-order correlations as well as the partial correlations for the three nature connectedness variables and well-being are presented in Table $3^{3}$. The magnitude of the correlations between the three nature connectedness measures and the well-being variables was somewhat smaller but remained significant when controlling for neighborhood connectedness and demographics.

\section{Neighborhood Tree Canopy, Health Perceptions, and Well-Being}

To examine how the density of trees might be correlated with nature connectedness (and certain natural features) and wellbeing we conducted correlation analyses in the subsample of participants with tree canopy data $(n=36)$, controlling for gender, income, and age ${ }^{4}$. We also tested these relationships

\footnotetext{
${ }^{3}$ The same relationships between trees, wildlife, nature connectedness and the well-being variables were also tested using regression equations. The results were consistent with the correlational findings.

${ }^{4}$ Our main goal was not to compare respondents with and without tree canopy data, however we used ANOVA and Chi square tests to compare the two types of respondents on demographic and outcome variables. There was no difference between the participants with and without tree canopy estimates, in terms of age, length of residence, or education. Participants not included in the tree canopy estimates had higher annual income $(M=67,344, S D=41,660)$ compared to those included in the tree canopy analyses $(M=43,697 S D=30,091), F_{(1,95)}=8.36, p$

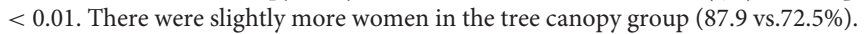
Not surprisingly, a smaller proportion of those with tree canopy data (i.e., within the city) were living in a single-unit home $(60.6 \%)$ compared to the respondents
} 
TABLE 3 | Correlations between connectedness, health perceptions, and well-being.

\begin{tabular}{|c|c|c|c|c|c|c|c|c|c|c|c|c|}
\hline$(N=102)$ & 1 & 2 & 3 & 4 & 5 & 6 & 7 & 8 & 9 & 10 & 11 & 12 \\
\hline 1. Connectedness-trees & - & & & & & & & & & & & \\
\hline 2. Connectedness-wildlife & $0.75^{\star \star}$ & - & & & & & & & & & & \\
\hline 4. Connectedness-neighborhood/neighbors & $0.36^{\star \star}$ & $0.26^{\star \star}$ & $0.34^{\star \star}$ & - & & & & & & & & \\
\hline 5. Active time in nature & 0.16 & $0.24^{\star}$ & $0.22^{\star}$ & 0.16 & - & & & & & & & \\
\hline 8. Psychological Distress (GHQ) & $\begin{array}{l}-0.20^{\dagger} \\
(-0.08)\end{array}$ & $\begin{array}{c}-0.26^{\star} \\
\left(-\mathbf{0 . 1 9 ^ { \dagger }}\right)\end{array}$ & $\begin{array}{c}-0.32^{\star \star} \\
(-\mathbf{0 . 2 4})\end{array}$ & $-0.34^{\star \star}$ & $-0.22^{*}$ & -0.08 & -0.05 & - & & & & \\
\hline 9. Physical Distress (PILL) & $\begin{array}{r}-0.09 \\
(0.02)\end{array}$ & $\begin{array}{c}-0.11 \\
(-0.02)\end{array}$ & $\begin{array}{c}-0.21^{*} \\
(-0.12)\end{array}$ & -0.15 & $-0.29^{\star \star}$ & -0.04 & -0.03 & $0.30^{\star \star}$ & - & & & \\
\hline 10. Positive Affect & $\begin{array}{l}0.37^{\star \star} \\
\left(\mathbf{0 . 2 6 ^ { \star } )}\right.\end{array}$ & $\begin{array}{l}0.29^{\star \star} \\
\left.(\mathbf{0 . 2 2})^{\star}\right)\end{array}$ & $\begin{array}{l}0.34^{\star \star} \\
\left(\mathbf{0 . 2 5 ^ { \star }}\right)\end{array}$ & $0.39^{\star \star}$ & $0.26^{\star \star}$ & 0.10 & 0.14 & $-0.63^{\star \star}$ & $-0.33^{\star \star}$ & - & & \\
\hline 12. Nature Positive Affect & $\begin{array}{l}0.31^{\star \star} \\
(\mathbf{0 . 2 5})\end{array}$ & $\begin{array}{l}0.22^{\star} \\
\left(\mathbf{0 . 1 8 ^ { \dagger }}\right)\end{array}$ & $\begin{array}{l}0.26^{\star} \\
\left(\mathbf{0 . 1 9} \mathbf{9}^{\dagger}\right)\end{array}$ & $0.21^{*}$ & 0.14 & -0.13 & $0.21^{*}$ & $-0.33^{\star *}$ & $-0.21^{*}$ & $0.60^{\star \star}$ & -0.09 & - \\
\hline 13. Vitality & 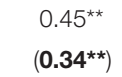 & $\begin{array}{c}0.32^{\star \star} \\
\left(\mathbf{0 . 2 4} 4^{\star}\right)\end{array}$ & 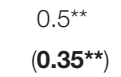 & $0.43^{*}$ & $0.33^{\star *}$ & 0.16 & 0.13 & $-0.57^{\star \star}$ & $-0.38^{\star \star}$ & $0.77^{\star \star}$ & $-0.48^{\star \star}$ & $0.48^{* \star}$ \\
\hline
\end{tabular}

Partial correlations between connection with trees/wildlife/nature and well-being, controlling for gender, income, age, and neighbors/neighborhood connectedness, are in parentheses. The correlations that remain significant are in bold.

${ }^{\dagger} p<0.10 .{ }^{*} p<0.05 .{ }^{* *} p<0.01$.

using a regression approach (correlational findings for tree canopy coverage and all study variables are presented in Table 4; regression results are reported in Table 5). Tree canopy density correlated positively with all aspects of nature connectedness. People with more tree canopy have a slightly stronger relationship with nature (including trees and wildlife) than those with fewer trees nearby. The density of neighborhood trees was unrelated to neighborhood connectedness or any of the time use reports for outdoor activities (we noted a trend in the expected direction, however, for tree canopy and time spent in the garden or yard).

We expected that people living in neighborhoods with more tree canopy would report better overall health, but this was only partly the case. Those living with more trees in their neighborhood reported better psychological health, i.e., lower levels of distress and marginally better mood (the correlation for tree canopy and PA was in the expected direction but did not reach significance). Tree canopy was unrelated to physical health perceptions.

from areas outside the two postal code sampling areas (97.1\%) where fewer apartment buildings exist. Fewer tree canopy participants were retired $(33.3 \%$ compared to $60.9 \%)$. Neighborhood connectedness was significantly stronger for those without tree canopy data $(M=3.89, S D=1.42)$ compared to those with it $(M$ $=2.71, S D=0.98), F_{(1,100)}=18.37, p<0.01$. The respondents with tree canopy data were slightly less happy: marginally lower on positive affect $(M=3.17, S D=$ 0.48 ; non canopy group: $M=3.38, S D=0.66), F_{(1,100)}=2.80, p<0.10$, and higher on negative affect $(M=2.13, S D=0.71$; non canopy group: $M=1.77, S D=0.68)$, $F_{(1,100)}=5.93, p<0.05$. Those with canopy data reported spending fewer hours being active in nature over the previous week $(M=2.12, S D=2.84$; non canopy group: $M=5.94, S D=8.79), F_{(1,100)}=5.91, p<0.05$.
TABLE 4 | Correlations between neighborhood tree canopy and connectedness, health perceptions, and well-being.

\begin{tabular}{lcc}
\hline \multirow{2}{*}{$(\boldsymbol{N}=\mathbf{3 6 )}$} & \multicolumn{2}{c}{ Tree canopy } \\
\cline { 2 - 3 } & $\boldsymbol{r}$ & Partial $\boldsymbol{r}$ \\
\hline Connectedness with trees & $0.35^{\star}$ & $0.37^{\star}$ \\
Connectedness with wildlife & $0.41^{\star}$ & $0.42^{\star}$ \\
Connectedness with nature & $0.41^{\star}$ & $0.42^{\star}$ \\
Connectedness with neighborhood/neighbors & 0.22 & 0.06 \\
Active time in nature & -0.08 & -0.10 \\
Time in garden or yard & 0.20 & 0.21 \\
Time visiting a park & 0.07 & 0.11 \\
Psychological distress (GHQ) & $-0.50^{\star \star}$ & $-0.44^{\star}$ \\
Physical distress (PILL) & -0.13 & -0.19 \\
Positive affect & 0.20 & 0.28 \\
Negative affect & -0.05 & -0.05 \\
Nature positive affect & 0.01 & 0.10 \\
Vitality & 0.11 & 0.18 \\
\hline
\end{tabular}

Partial correlations controlled for gender, income, and age.

${ }^{\dagger} p<0.10 .{ }^{*} p<0.05 .{ }^{* *} p<0.01$.

\section{DISCUSSION}

The purpose of the study was to explore the potential benefits of nearby nature-and trees, in particular-for well-being, as well as subjective connectedness. We also expected that people living in neighborhoods with more tree canopy would report greater well-being (positive affect and vitality) and less ill-being 
TABLE 5 | Regression analyses for neighborhood tree canopy and connectedness, health perceptions, and well-being, controlling for demographics $(n=36)$.

\begin{tabular}{|c|c|c|}
\hline Tree canopy-connectedness with trees & Step $1 \beta$ & Step $2 \beta$ \\
\hline Gender & -0.16 & -0.08 \\
\hline Income & -0.10 & -0.14 \\
\hline Age & 0.01 & -0.11 \\
\hline Tree canopy & & $0.39^{\star}$ \\
\hline$\Delta R^{2}$ & 0.03 & 0.13 \\
\hline$\Delta F$ & 0.30 & $4.37^{\star}$ \\
\hline \multicolumn{3}{|l|}{ Tree canopy-connectedness with wildlife } \\
\hline Gender & -0.09 & 0.00 \\
\hline Income & -0.03 & -0.08 \\
\hline Age & 0.02 & -0.11 \\
\hline Tree canopy & & $0.44^{\star}$ \\
\hline$\Delta R^{2}$ & 0.01 & 0.17 \\
\hline$\Delta F$ & 0.07 & $5.97^{\star}$ \\
\hline \multicolumn{3}{|l|}{ Tree canopy-connectedness with nature } \\
\hline Gender & -0.20 & -0.11 \\
\hline Income & -0.11 & -0.16 \\
\hline Age & 0.04 & -0.10 \\
\hline Tree canopy & & $0.44^{*}$ \\
\hline$\Delta R^{2}$ & 0.05 & $0.17^{\star}$ \\
\hline$\Delta F$ & 0.47 & $6.06^{\star}$ \\
\hline \multicolumn{3}{|c|}{$\begin{array}{l}\text { Tree canopy-connectedness with connectedness } \\
\text { with neighborhood/neighbors }\end{array}$} \\
\hline Gender & -0.21 & -0.20 \\
\hline Income & $0.28^{t}$ & $0.28^{\dagger}$ \\
\hline Age & $0.46^{\star \star}$ & $0.44^{*}$ \\
\hline Tree canopy & & 0.06 \\
\hline$\Delta R^{2}$ & 0.27 & 0.00 \\
\hline$\Delta F$ & $3.70^{\star}$ & 0.11 \\
\hline \multicolumn{3}{|l|}{ Tree canopy- active time in nature } \\
\hline Gender & -0.22 & -0.25 \\
\hline Income & -0.15 & -0.14 \\
\hline Age & -0.03 & 0.01 \\
\hline Tree canopy & & -0.11 \\
\hline$\Delta R^{2}$ & 0.07 & 0.01 \\
\hline$\Delta F$ & 0.73 & 0.32 \\
\hline \multicolumn{3}{|l|}{ Tree canopy-time in garden or yard } \\
\hline Gender & 0.13 & 0.17 \\
\hline Income & 0.04 & 0.01 \\
\hline Age & 0.07 & 0.00 \\
\hline Tree canopy & & 0.22 \\
\hline$\Delta R^{2}$ & 0.03 & 0.04 \\
\hline$\Delta F$ & 0.26 & 1.34 \\
\hline \multicolumn{3}{|l|}{ Tree canopy-time visiting a park } \\
\hline Gender & -0.07 & -0.05 \\
\hline Income & -0.10 & -0.11 \\
\hline Age & -0.12 & -0.15 \\
\hline Tree canopy & & 0.11 \\
\hline$\Delta R^{2}$ & 0.03 & 0.01 \\
\hline$\Delta F$ & 0.29 & 0.33 \\
\hline
\end{tabular}

(Continued)
TABLE 5 | Continued

Tree canopy-connectedness with trees

Step $1 \beta$

Step $2 \beta$

Tree canopy-psychological distress (GHQ)

Gender

$0.20 \quad 0.11$

Income

$-0.14 \quad-0.09$

Age

Tree canopy

$\Delta R^{2}$

$\Delta F$

Tree canopy-physical distress (PILL)

Gender

Income

Age

Tree canopy

$\Delta R^{2}$

$\Delta F$

Tree canopy-positive affect

Gender

Income

Age

Tree canopy

$\Delta R^{2}$

$\Delta F$

Tree canopy-negative affect

Gender

Income

Age

Tree canopy

$\Delta R^{2}$

$\Delta F$

Tree canopy-nature positive affect

$-0.22 \quad-0.08$

$-0.45^{*}$

$0.09 \quad 0.18$

0.95

$7.12^{*}$

Gender

$\begin{array}{ll}-0.07 & -0.11\end{array}$

$0.04 \quad 0.06$

$0.12 \quad 0.19$

$-0.20$

$0.02 \quad 0.03$

$0.17 \quad 1.02$

Income

Age

Tree canopy

$\Delta R^{2}$

$\Delta F$

Tree canopy-vitality

Gender

Income

Age

Tree canopy

$\Delta R^{2}$

$0.25 \quad 0.31^{\dagger}$

0.22

0.19

$-0.12$

$-0.21$

0.29

0.07

0.11

2.54

1.19

$\begin{array}{ll}-0.02 & -0.03 \\ -0.24 & -0.23\end{array}$

$-0.24$

-0.23
-0.08

$-0.06$

$-0.06$

$0.06 \quad 0.00$

$0.68 \quad 0.09$

$\Delta F$

0.11

0.13

0.14

0.13

$-0.29$

$-0.32$

0.10

$0.11 \quad 0.01$

1.20

0.31

Gender is coded $0=$ female, $1=$ male. $\beta=$ standardized betas

${ }^{\dagger} p<0.10 .{ }^{\star} p<0.05$. ${ }^{\star *} p<0.01$.

(negative physical and mental health perceptions, negative affect) than people living in neighborhoods with less tree density. The findings are mixed in that connectedness with various aspects of nature more consistently predicted positive functioning (especially vitality) whereas the physical presence of trees attenuated negative mental (but not physical) health perceptions. 
Connectedness with nature appears related to the features of the natural environment. The more tree canopy in a person's neighborhood, the more likely that person reported feeling connected to their neighborhood and neighbors, to trees and wildlife, and to nature in general. Without further research, it is not possible to determine whether people who feel connected with nature seek out a neighborhood with more trees, or whether living in tree-dense communities enhances connectedness (or both). In other words, further work is needed to establish the cause and direction of this relationship. With the pressing need to enhance or restore the quality of urban spaces, community tree planting seems a particularly promising strategy for fostering connectedness with nature (Whitburn et al., 2018). We need research to track the effects of urban naturalization projects, however, and whether this leads to more pro-environmental attitudes as well as human health improvements, and why (Hartig and Kahn, 2016). The mechanisms underlying nature's psychological benefits are not entirely understood but as the most ubiquitous and salient natural feature in many cities, trees are worthy of more attention (urban agriculture and the health and nature connectedness benefits of gardening are another priority, cf. Uhlmann et al., 2018). Trees are not only important for the ecosystem services they provide, but for their aesthetics and psychological impact on humans. Mature and old growth trees enhance neighborhood biodiversity and provide opportunities to view and learn about wildlife. When people are able to observe and identify backyard birds, for example, they develop a stronger connection to them (Cox and Gaston, 2015). Existing research indicates people with a strong sense of nature connectedness seek out biodiversity (Shanahan et al., 2015). It seems plausible that a neighborhood with richer flora and fauna will promote connectedness. Having nature nearby may also buffer against feelings of social disconnection (Cartwright et al., 2018). Thus, trees and wildlife (even if viewed through a window; cf. Kaplan, 1993) could be of added benefit to older adults who may have mobility issues (hindering them from getting out in nature and connecting with others).

Based on the existing evidence that green space improves physical and mental health, it seemed reasonable to expect that the more tree canopy in a person's neighborhood, the more time they would spend outside. A tree-filled neighborhood seems likely to induce people to spend time outdoors on walks, hikes, runs, bicycle rides, in the yard, or in parks. Neighborhood greenspace is associated with physical activity, but much of the research focus has been on parks and trails (Hartig et al., 2014; Kuo, 2015). Somewhat surprisingly, people with more nearby trees did not report spending more time being active in nature or visiting parks. Participants reported spending slightly more time in their yard if their neighborhood had more trees but this was only a non-significant trend. Given that it can be uncomfortable to be outside during the winter months in Canada, nature connectedness may be a better predictor of outdoor activities during more pleasant seasons (cf. Nisbet et al., 2011; Brooks et al., 2017). We are optimistic that future studies will establish relationships between trees and outdoor activity in the warmer months. Still, we are encouraged by the fact that some Peterborough residents were active in nature and visiting parks in
December and January. Efforts to promote nature connectedness may require education to raise awareness of nature's benefits in all seasons. During the winter months people may need specific strategies and suggestions for how to stay connected with nature, such as bird watching and animal tracking (e.g., Pathway to Stewardship and Kinship project, 2019).

The presence of trees was associated with somewhat better psychological health. Negative mental health perceptions were inversely related to the density of trees in respondents' neighborhoods. In other words, people who reported poor mental health had fewer trees around their homes (and this relationship remained when controlling for demographic variables). There was no evidence in this study, however, that people living around more trees benefitted from fewer symptoms associated with illness. In this sample, it appears the benefits of living with trees nearby are mainly for mental health or psychological well-being. Our findings align with previous work exploring nature's effects on depression (e.g., Berman et al., 2012). Rumination is a symptom of depression, where an almost compulsive attention is paid to causes of distress. The restorative benefits nature has on attention (Kaplan, 1995; Kaplan and Berman, 2010) may partly explain the reduced number of depressive symptoms reported in the current study. In fact, being in nature not only reduces repeated negative thinking, but after walking in forested areas the prefrontal cortex of people's brains-the area associated with rumination-is less active (Bratman et al., 2015). Nature's influence on attention restoration and reducing negative thoughts is distinguishable beyond the effects of exercise (Berman et al., 2012; Bratman et al., 2015; Olafsdottir et al., 2018). Trees, as a salient element of the natural world, may provide restorative associations for people that live around them in urban environments. Regardless of the mechanisms involved, the relationship neighborhood trees have with (reduced) depressive symptoms make them a feature of the urban environment community stakeholders, policy makers, and everyday individuals should be paying attention to, given the aging population.

Further research comparing high- and low-density tree canopy will help to establish whether trees have greater benefits for particular populations or different types of communities (e.g., those living in urban areas with less natural surfaces, or poor air quality). Additional studies that monitor nature connectedness in people who move to a different type of neighborhood, or using pre-post designs to assess the effects of tree loss will help to identify what factors shape interconnectedness with features of the local environment. Older adults have already indicated their preferences for neighborhoods with trees and vegetation (Borst et al., 2008; Van Cauwenberg et al., 2014). Trees (and the wildlife they support) could be a simple way to enhance mental health perceptions as well as interconnectedness within communities.

Consistent with Cheesbrough et al.'s (2019) qualitative work, the current findings suggest numerous elements of the natural environment contribute to well-being. The sense of connectedness people have with various living things, as well as the broader concept of nature, predicted mood, vitality, and less distress, but in different ways. Because conceptualizations of nature are subjective, the elements of nature that come 
to mind when reporting on connectedness are likely different from person to person. Local culture, values, biodiversity, and knowledge likely affect subjective definitions, and thus reported connectedness. Cultural narratives and historical injustices may even make people mistrustful of urban tree-planting efforts (Carmichael and McDonough, 2019). People's engagement with and attitudes toward nature can be influenced by their culture's beliefs, social structures, and affluence (Milfont, 2012; Milfont and Schultz, 2016), and there is evidence that a variety of factors can influence people's relationships with nature (e.g., Wilhelm-Rechmann et al., 2014). Nature connectedness may not only be influenced by spiritual, political, economic, and educational differences, but by geographical (climate zones) and ecological (flora and fauna) differences as well. Over $60 \%$ of the research on nature connectedness has originated from North America, Australia, the United Kingdom, and the Netherlands (Restall and Conrad, 2015; Ives et al., 2017, 2018), rendering an understanding of human-nature relationships incomplete. More cross-cultural comparisons of human-nature relationships are needed to determine the replicability of these findings, and how the links with health and well-being might vary globally.

\section{Limitations}

Although this research is correlational and relied on self-selection into the study, it included community participants and an under-studied but important demographic-older adults. To our knowledge, no existing work has investigated individual differences in connections to trees, and the links with other types of connectedness, and well-being. The sub-sample of participants with tree-canopy data allowed us to test these novel questions but the small sample reduced the power in our analyses. The cross-sectional nature of the study provides a snapshot of observation limited in time; inferences are restricted to descriptions of relationships. Longitudinal and experimental design is needed to establish any causal relationship between connectedness with trees, wildlife, and well-being. The lack of foliage on many trees during the winter also limits the generalization of our findings. The relationship between tree canopy density, nature connectedness, and well-being may differ during the spring, summer, and fall when there is greater diversity in the type and color of vegetation. Season may also have limited nature's effects on physical symptoms. With less time outdoors, people may not be immersed enough in nature to

\section{REFERENCES}

Akbari, H., Pomerantz, M., and Taha, H. (2001). Cool surfaces and shade trees to reduce energy use and improve air quality in urban areas. Solar Energy 70, 295-310. doi: 10.1016/S0038-092X(00)00089-X

Berman, M. G., Jonides, J., and Kaplan, S. (2008). The cognitive benefits of interacting with nature. Psychol. Sci. 19, 1207-1212. doi: 10.1111/j.1467-9280.2008.02225.x

Berman, M. G., Kross, E., Krpan, K. M., Askren, M. K., Burson, A., Deldin, P. J., et al. (2012). Interacting with nature improves cognition and affect for individuals with depression. J. Affect. Disord. 140, 300-305. doi: $10.1016 /$ j.jad.2012.03.012

Borst, H. C., Miedema, H. M. E., de Vries, S. I., Graham, J. M. A., and van Dongen, J. E. F. (2008). Relationships between street characteristics and perceived experience improvements in immune functioning, for example (cf. Tsunetsugu et al., 2010).

\section{CONCLUSION}

Connection to trees has benefits for well-being. In this study of urban residents, the greater the tree canopy density, the more connected people were to trees, wildlife, and nature in general. In order to develop connectedness with trees, people likely need them to be present nearby. More work is needed to establish the cause and direction of these relationships, but our findings suggest people could benefit from more exposure to nearby nature. Trees in urban centres provide benefits beyond habitat for wildlife, or stormwater management and air quality. They offer opportunities to develop a connection with the neighborhood and local species of birds and mammals. Fostering connections with local features of the natural environment, including trees, is a promising and cost-effective strategy to improve both human and environmental health.

\section{DATA AVAILABILITY STATEMENT}

The datasets generated for this study are available on request to the corresponding author.

\section{ETHICS STATEMENT}

The studies involving human participants were reviewed and approved by Trent University Research Ethics Committee. The patients/participants provided their written informed consent to participate in this study.

\section{AUTHOR CONTRIBUTIONS}

The study was comprised of DS's honors thesis. DS contributed the research idea, collected data, conducted analyses, and contributed sections to the manuscript. EN conducted analyses and drafted the manuscript. DL contributed research and writing to the introduction and discussion sections.

\section{ACKNOWLEDGMENTS}

We thank members of the NR lab for help with tree canopy sampling.

attractiveness for walking reported by elderly people. J. Environ. Psychol. 28, 353-361. doi: 10.1016/j.jenvp.2008.02.010

Bratman, G. N., Hamilton, J. P., Hahn, K. S., Daily, G. C., and Gross, J. J. (2015). Nature experience reduces rumination and subgenual prefrontal cortex activation. Proc. Natl. Acad. Sci. U.S.A. 112, 8567-72. doi: 10.1073/pnas.1510459112

Brooks, A. M., Ottley, K. M., Arbuthnott, K. D., and Sevigny, P. (2017). Nature-related mood effects: Season and type of nature contact. J. Environ. Psychol. 54, 91-102. doi: 10.1016/j.jenvp.2017. 10.004

Capaldi, C. A., Passmore, H.-A., Nisbet, E. K., Zelenski, J. M., and Dopko, R. L. (2015). Flourishing in nature: a review of the benefits of connecting with nature and its application as a wellbeing intervention. Int. J. Wellbeing 5, 1-16. doi: 10.5502/ijw.v5i4.449 
Carmichael, C. E., and McDonough, M. H. (2019). Community stories: explaining resistance to street tree-planting programs in Detroit, Michigan, USA. Soc. Nat. Resour. 32, 588-605. doi: 10.1080/08941920.2018. 1550229

Cartwright, B. D. S., White, M. P., and Clitherow, T. J. (2018). Nearby nature 'buffers' the effect of low social connectedness on adult subjective wellbeing over the last 7 days. Int. J. Environ. Res. Public Health 15:1238. doi: 10.3390/ijerph15061238

Cheesbrough, A., Garvin, T., and Nykiforuk, C. I. J. (2019). Everyday wild: urban areas, health, and well-being. Health Place 56, 43-52. doi: 10.1016/j.healthplace.2019.01.005

CIHI (2011). Canadian Institute for Health Information: Urban Physical Environments and Health Inequalities. Available online at: https://secure.cihi. ca/free_products/cphi_urban_physical_environments_en.pdf (accessed May 11, 2020).

Colléony, A., Prévot, A.-C., Saint Jalme, M., and Clayton, S. (2017). What kind of landscape management can counteract the extinction of experience? Landsc. Urban Plan. 159, 23-31. doi: 10.1016/j.landurbplan.2016.11.010

Cox, D. T., and Gaston, K. J. (2015). Likeability of garden birds: importance of species knowledge \& richness in connecting people to nature. PLoS ONE 10:e0141505. doi: 10.1371/journal.pone.0141505

Donovan, G. H., Butry, D. T., Michael, Y. L., Prestemon, J. P., Liebhold, A. M., Gatziolis, D., et al. (2013). The relationship between trees and human health. Am. J. Prevent. Med. 44, 139-145. doi: 10.1016/j.amepre.2012.09.066

Donovan, G. H., Michael, Y. L., Butry, D. T., Sullivan, A. D., and Chase, J. M. (2011). Urban trees and the risk of poor birth outcomes. Health Place. 17, 390-393. doi: 10.1016/j.healthplace.2010.11.004

Escobedo, F. J., and Nowak, D. J. (2009). Spatial heterogeneity and air pollution removal by an urban forest. Landsc. Urban Plan. 90, 102-110. doi: 10.1016/j.landurbplan.2008.10.021

Faber Taylor, A., and Kuo, F. E. (2009). Children with attention deficits concentrate better after walk in the park. J. Attent. Disord. 12 402-409. doi: $10.1177 / 1087054708323000$

Faber Taylor, A., Kuo, F. E., and Sullivan, W. C. (2001). Coping with ADD: the surprising connection to green play settings. Environ. Behav. 33, 54-77. doi: $10.1177 / 00139160121972864$

Faber Taylor, A., Kuo, F. E., and Sullivan, W. C. (2002). Views of nature and selfdiscipline: evidence from inner city children. J. Environ. Psychol. 22, 49-63. doi: 10.1006/jevp.2001.0241

Flowers, E. P., Freeman, P., and Gladwell, V. F. (2016). A cross-sectional study examining predictors of visit frequency to local green space and the impact this has on physical activity levels. BMC Public Health 16:420. doi: 10.1186/s12889-016-3050-9

Forouzanfar, M. H., Alexander, L., Anderson, H. R., Bachman, V. F., Biryukov, S., Brauer, M., et al. (2015). Global, regional, and national comparative risk assessment of 79 behavioural, environmental and occupational, and metabolic risks or clusters of risks in 188 countries, 1990-2013: a systematic analysis for the global burden of disease study 2013. Lancet 386, 2287-2323. doi: 10.1016/S0140-6736(15)00128-2

Fuller, R. A., Irvine, K. N., Devine-Wright, P., Warren, P. H., and Gaston, K. J. (2007). Psychological benefits of green space increase with biodiversity. Biol. Lett. 3, 390-394. doi: 10.1098/rsbl.2007.0149

Gifford, R. (2008). Psychology's essential role in alleviating the impacts of climate change. Can. Psychol. Psychol. Can. 49, 273-280. doi: 10.1037/a00 13234

Goldberg, D. P., Gater, R., Sartorius, N., Ustun, T. B., Piccinelli, M., Gureje, O., et al. (1997). The validity of two versions of the GHQ in the WHO study of mental illness in general health care. Psychol. Med. 27, 191-197. doi: $10.1017 /$ S0033291796004242

Hartig, T., and Kahn, P. H. (2016). Living in cities, naturally. Science 352, 938-940. doi: $10.1126 /$ science.aaf3759

Hartig, T., Mitchell, R., de Vries, S., and Frumkin, H. (2014). Nature and health. Annu. Rev. Public Health 35, 207-28. doi: 10.1146/annurev-publhealth-032013-182443

Hur, M., Nasar, J. L., and Chun, B. (2010). Neighborhood satisfaction, physical and perceived naturalness and openness. J. Environ. Psychol. 30, 52-59. doi: 10.1016/j.jenvp.2009.05.005

IPCC (2014). Climate Change 2014: Synthesis Report. Available online at: https:// www.ipcc.ch/site/assets/uploads/2018/05/SYR_AR5_FINAL_full_wcover.pdf (accessed May 11, 2020).
Ives, C. D., Abson, D. J., von Wehrden, H., Dorninger, C., Klaniecki, K., and Fischer, J. (2018). Reconnecting with nature for sustainability. Sust. Sci. 13, 1389-1397. doi: 10.1007/s11625-018-0542-9

Ives, C. D., Giusti, M., Fischer, J., Abson, D. J., Klaniecki, K., Dorninger, C., et al. (2017). Human-nature connection: a multidisciplinary review. Curr. Opin. Environ. Sust. 26-27, 106-113. doi: 10.1016/j.cosust.2017.05.005

Jiang, B., Li, D., Larsen, L., and Sullivan, W. C. (2016). A dose-response curve describing the relationship between urban tree cover density and self-reported stress recovery. Environ. Behav. 48, 607-629. doi: 10.1177/0013916514552321

Kaplan, R. (1993). The role of nature in the context of the workplace. Landsc. Urban Plann. 26, 193-201. doi: 10.1016/0169-2046(93)90016-7

Kaplan, S. (1995). The restorative benefits of nature: toward an integrative framework. J. Environ. Psychol. 15, 169-182. doi: 10.1016/0272-4944(95)90001-2

Kaplan, S. (2001). Meditation, restoration and the management of mental fatigue. Environ. Behav. 33, 480-506. doi: 10.1177/00139160121973106

Kaplan, S., and Berman, M. G. (2010). Directed attention as a common resource for executive functioning and self-regulation. Perspect. Psychol. Sci. 5, 43-57. doi: $10.1177 / 1745691609356784$

Kardan, O., Gozdyra, P., Misic, B., Moola, F., Palmer, L. J., Paus, T., et al. (2015). Neighborhood greenspace and health in a large urban center. Sci. Rep. 5:11610. doi: $10.1038 /$ srep 11610

Klemm, W., Heusinkveld, B. G., Lenzholzer, S., and van Hove, B. (2015). Street greenery and its physical and psychological impact on thermal comfort. Landsc. Urban Plan. 138, 87-98. doi: 10.1016/j.landurbplan.2015.02.009

Kuo, F. E., and Faber Taylor, A. (2004). A potential natural treatment for attentiondeficit/hyperactivity disorder: evidence from a national study. Am. J. Public Health 94, 1580-1587. doi: 10.2105/AJPH.94.9.1580

Kuo, M. (2015). How might contact with nature promote human health? Promising mechanisms and a possible central pathway. Front. Psychol. 6:1093. doi: 10.3389/fpsyg.2015.01093

Kuo, M., Browning, M. H. E. M., and Penner, M. L. (2018). Do lessons in nature boost subsequent classroom engagement? Refueling students in flight. Front. Psychol. 8:2253. doi: 10.3389/fpsyg.2017.02253

Leary, M. R., Tipsord, J. M., and Tate, E. B. (2008). "Allo-inclusive identity: incorporating the social and natural worlds into one's sense of self," in Transcending Self-Interest: Psychological Explorations of the Quiet Ego, eds H. Wayment and J. Bauer (Washington, DC: American Psychological Association), 137-147.

Lin, B. B., Fuller, R. A., Bush, R., Gaston, K. J., and Shanahan, D. F. (2014). Opportunity or orientation? Who uses urban parks and why. PLOS ONE 9:e87422. doi: 10.1371/journal.pone.0087422

Lin, B. B., Gaston, K. J., Fuller, R. A., Wu, D., Bush, R., and Shanahan, D. F. (2017). How green is your garden? Urban form and socio-demographic factors influence yard vegetation, visitation, and ecosystem service benefits. Landsc. Urban Plan. 157, 239-246. doi: 10.1016/j.landurbplan.2016.07.007

Luck, G. W., Davidson, P., Boxall, D., and Smallbone, L. (2011). Relations between urban bird and plant communities and human well-being and connection to nature. Conserv. Biol. 25, 816-826. doi: 10.1111/j.1523-1739.2011.01685.x

Matz, C. J., Stieb, D. M., Davis, K., Egyed, M., Rose, A., Chou, B., et al. (2014). Effects of age, season, gender and urban-rural status on time-activity: canadian human activity pattern survey 2 (CHAPS 2). Int. J. Environ. Res. Public Health 11, 2108-2124. doi: 10.3390/ijerph110202108

Mayer, F. S., and Frantz, C. M. (2004). The connectedness to nature scale: a measure of individuals' feeling in community with nature. J. Environ. Psychol. 24, 503-515. doi: 10.1016/j.jenvp.2004.10.001

Milfont, T. L. (2012). "Cultural differences in environmental engagement," in The Oxford Handbook of Environmental and Conservation Psychology, ed S. D. Clayton (New York, NY: Oxford University Press), 181-200.

Milfont, T. L., and Schultz, P. W. (2016). Culture and the natural environment. Curr. Opin. Psychol. 8, 194-199. doi: 10.1016/j.copsyc.2015.09.009

Mitchell, R., and Popham, F. (2008). Effect of exposure to natural environment on health inequalities: an observational population study. Lancet 372, 1655-1660. doi: 10.1016/S0140-6736(08)61689-X

Nisbet, E., Zelenski, J. M., and Grandpierre, Z. (2019). Mindfulness in nature enhances connectedness and mood. Ecopsychology 11, 81-91. doi: 10.1089/eco.2018.0061

Nisbet, E. K., and Zelenski, J. M. (2011). Underestimating nearby nature: affective forecasting errors obscure the happy path to sustainability. Psychol. Sci. 22, 1101-1106. doi: 10.1177/0956797611418527 
Nisbet, E. K., Zelenski, J. M., and Murphy, S. A. (2009). The nature relatedness scale: linking individuals' connection with nature to environmental concern and behavior. Environ. Behav. 41, 715-740. doi: 10.1177/0013916508318748

Nisbet, E. K., Zelenski, J. M., and Murphy, S. A. (2011). Happiness is in our nature: exploring nature relatedness as a contributor to subjective well-being. J. Happiness Stud. 12, 303-322. doi: 10.1007/s10902-010-9197-7

Nowak, D. J., and Greenfield, E. J. (2010). Evaluating the national land cover database tree canopy and impervious cover estimates across the conterminous United States: a comparison of photo-interpreted estimates. Environ. Manag. 46, 378-390. doi: 10.1007/s00267-010-9536-9

Nowak, D. J., and Greenfield, E. J. (2012). Tree and impervious cover change in U.S. cities. Urban For. Urban Green. 11, 21-30. doi: 10.1016/j.ufug.2011.11.005

Nowak, D. J., Hirabayashi, S., Bodine, A., and Greenfield, E. (2014). Tree and forest effects on air quality and human health in the United States. Environ. Pollut. 193, 119-129. doi: 10.1016/j.envpol.2014.05.028

Olafsdottir, G., Cloke, P., Schulz, A., van Dyck, Z., Eysteinsson, T., Thorleifsdottir, B., et al. (2018). The health benefits of walking in nature: a randomized controlled study under conditions of real-life stress. Environ. Behav. 52, 248-274. doi: 10.1177/0013916518800798

Park, B. J., Tsunetsugu, Y., Kasetani, T., Kagawa, T., and Miyazaki, Y. (2010). The physiological effects of shinrin-yoku (taking in the forest atmosphere or forest bathing): evidence from field experiments in 24 forests across Japan. Environ. Health Prevent. Med. 15, 18-26. doi: 10.1007/s12199-009-0086-9

Pathway to Stewardship and Kinship project (2019). Retrieved from: http:// pathwayproject.ca/landmarks/ (accessed May 11, 2020).

Pennebaker, J. W. (1982). The PILL: a trait measure. The Psychology of Physical Symptoms. Available online at: https://liberalarts.utexas.edu/ psychology/faculty/pennebak\#helpful-questionnaires (accessed May 11, 2020).

Pennebaker, J. W., and Epstein, D. (1983). Implicit psychophysiology: effects of common beliefs and idiosyncratic physiological responses symptom reporting. J. Pers. 51, 468-496. doi: 10.1111/j.1467-6494.1983. tb00341.x

Pergams, O. R. W., and Zaradic, P. A. (2008). Evidence of a fundamental and pervasive shift away from nature-based recreation. Proc. Natl. Acad. Sci. U.S.A. 105, 2295-2300. doi: 10.1073/pnas.0709893105

Pyle, R. M. (1993). Thunder Trees: Lessons from an Urban Wildland. Boston, MA: Houghton Mifflin.

Ratcliffe, E., Gatersleben, B., and Sowden, P. T. (2013). Bird sounds and their contributions to perceived attention restoration and stress recovery. J. Environ. Psychol. 36, 221-228. doi: 10.1016/j.jenvp.2013.08.004

Restall, B., and Conrad, E. (2015). A literature review of connectedness to nature and its potential for environmental management. J. Environ. Manag. 159, 264-278. doi: 10.1016/j.jenvman.2015.05.022

Rosenberg, K. V., Dokter, A. M., Blancher, P. J., Sauer, J. R., Smith, A. C., Smith, P. A., et al. (2019). Decline of the North American avifauna. Science 366, 120-124. doi: $10.1126 /$ science.aaw1313

Ryan, R. M., and Frederick, C. (1997). On energy, personality, and health: subjective vitality as a dynamic reflection of well-being. J. Pers. 65, 529-565. doi: 10.1111/j.1467-6494.1997.tb00326.x

Schultz, P. W. (2001). The structure of environmental concern: concern for self, other people, and the biosphere. J. Environ. Psychol. 21, 327-339. doi: 10.1006/jevp.2001.0227

Schultz, P. W. (2002). "Inclusion with nature: the psychology of human-nature relations," in Psychology of Sustainable Development, eds P. Schmuck and P. W. Schultz (Norwell, MA: Kluwer Academic), 62-78.

Shanahan, D. F., Lin, B. B., Gaston, K. J., Bush, R., and Fuller, R. A. (2015). What is the role of trees and remnant vegetation in attracting people to urban parks? Landsc. Ecol. 30, 153-165. doi: 10.1007/s10980-014-0113-0

Shields, M. (2008). Health Reports: Community Belonging and Self-perceived Health. Ottawa, ON: Statistics Canada. Retrieved from: http://www5.statcan.gc. $\mathrm{ca} /$ olc-cel/olc.action?ObjId=82-003-X200800210552\&ObjType=47\&lang=en

Soga, M., and Gaston, K. J. (2016). Extinction of experience: the loss of humannature interactions. Front. Ecol. Environ. 14:1225. doi: 10.1002/fee.1225

Stagoll, K., Lindenmayer, D. B., Knight, E., Fischer, J., and Manning, A. D. (2012). Large trees are keystone structures in urban parks. Conserv. Lett. 5, 115-122. doi: $10.1111 / j .1755-263 X .2011 .00216 . x$

Statistics Canada (2017). Focus on Geography Series, 2016 Census. Statistics Canada Catalogue no. 98-404-X2016001. Available online at: https://www12.statcan. gc.ca/census-recensement/2016/as-sa/fogs-spg/Facts-cma- eng.cfm?GC $=529 \&$ GK=CMA\&LANG=Eng (accessed May 11, 2020)
Tam, K.-P. (2013). Concepts and measures related to connection to nature: similarities and differences. J. Environ. Psychol. 34, 64-78. doi: 10.1016/j.jenvp.2013.01.004

Taylor, M. S., Wheeler, B. W., White, M. P., Economou, T., and Osborne, N. J. (2015). Research note: urban street tree density and antidepressant prescription rates-a cross-sectional study in London, UK. Landsc. Urban Plan. 136, 174-179. doi: 10.1016/j.landurbplan.2014.12.005

Tominaga, K., Watmough, S., and Ahern, J. (2008). Predicting tree survival in Ontario sugar maple (Acer saccharum) forests based on crown condition. Can. J. Forest Res. 37, 1730-41. doi: 10.1139/X08-021

Tsunetsugu, Y., Park, B.-J., and Miyazaki, Y. (2010). Trends in research related to "Shinrin-yoku" (taking in the forest atmosphere or forest bathing) in Japan. Environ. Health Prevent. Med. 15, 27-37. doi: 10.1007/s12199-009-0091-z

Turner, W. R., Nakamura, T., and Dinetti, M. (2004). Global urbanization and the separation of humans from nature. BioScience 54, 585-590. doi: 10.1641/00063568(2004)054[0585:GUATSO]2.0.CO2

Uhlmann, K., Lin, B. B., and Ross, H. (2018). Who cares? The importance of emotional connections with nature to ensure food security and wellbeing in cities. Sustainability 10, 1-16. doi: 10.3390/su10061844

UNEP (2015). The United Nations Environment Programme and the 2030 Agenda: Global Action for People and the Planet. Available online at: https:// www.unenvironment.org/resources/report/united-nations-environmentprogramme-and-2030-agenda-global-action-people-and (accessed May 11, 2020).

United Nations (2018). World Urbanization Prospects: The 2018 Revision. Available online at: https://population.un.org/wup/Publications/Files/WUP2018KeyFacts.pdf (accessed May 11, 2020).

Van Cauwenberg, J., Van Holle, V., De Bourdeaudhuij, I., Clarys, P., Nasar, J., Salmon, J., et al. (2014). Physical environmental factors that invite older adults to walk for transportation. J. Environ. Psychol. 38, 94-103. doi: 10.1016/j.jenvp.2013.12.012

Vos, P. E. J., Maiheu, B., Vankerkom, J., and Janssen, S. (2013). Improving local air quality in cities: to tree or not to tree? Environ. Pollut. 183, 113-122. doi: 10.1016/j.envpol.2012.10.021

Wang, Y., Hogg, E. H., Price, D. T., Edwards, J., and Williamson, T. (2014). Past and projected future changes in moisture conditions in the Canadian boreal forest. For. Chronicle 90, 678-691. doi: 10.5558/tfc2014-134

Watson, D., Clark, L. A., and Tellegen, A. (1988). Development and validation of brief measures of positive and negative affect: the PANAS scales. J. Pers. Soc. Psychol. 54, 1063-1070. doi: 10.1037/0022-3514.54. 6.1063

Whitburn, J., Linklater, W. L., and Milfont, T. (2018). Exposure to urban nature and tree planting are related to pro-environmental behavior via connection to nature, the use of nature for psychological restoration, and environmental attitudes. Environ. Behav. 51, 787-810. doi: 10.1177/00139165177 51009

Wilhelm-Rechmann, A., Cowling, R. M., and Difford, M. (2014). Responses of South African land-use planning stakeholders to the new ecological paradigm and the inclusion of nature in self scales: assessment of their potential as components of social assessments for conservation projects. Biol. Conserv. 180, 206-213. doi: 10.1016/j.biocon.2014.10.012

Zelenski, J. M., Dopko, R. L., and Capaldi, C. A. (2015). Cooperation is in our nature: nature exposure may promote cooperative and environmentally sustainable behavior. J. Environ. Psychol. 42, 24-31. doi: 10.1016/j.jenvp.2015.01.005

Zelenski, J. M., and Nisbet, E. K. (2014). Happiness and feeling connected: the distinct role of nature relatedness. Environ. Behav. 46, 3-23. doi: $10.1177 / 0013916512451901$

Conflict of Interest: The authors declare that the research was conducted in the absence of any commercial or financial relationships that could be construed as a potential conflict of interest.

Copyright $\odot 2020$ Nisbet, Shaw and Lachance. This is an open-access article distributed under the terms of the Creative Commons Attribution License (CC BY). The use, distribution or reproduction in other forums is permitted, provided the original author(s) and the copyright owner(s) are credited and that the original publication in this journal is cited, in accordance with accepted academic practice. No use, distribution or reproduction is permitted which does not comply with these terms. 